\title{
PROPAGANDA POLITIK TOKOH UTAMA DALAM NOVEL RASA MERDIKA KARYA SOEMANTRI
}

\author{
Agus Sulton \\ Universitas Hasyim Asy'ari Tebuireng Jombang \\ agus_sul@yahoo.com
}

\begin{abstract}
ABSTRAK
Penelitian ini hendak melihat propaganda politik yang dilakukan tokoh Soedjanmo, Sastro, dan Soedarmo dalam novel Rasa Merdika karya Soemantri. Propaganda politik yang disampaikan tokoh tersebut seputar kapitalisme, kemiskinan, dan kebijakan pemerintah yang merugikan rakyat. Metode penelitian ini menggunakan metode deskriptif kualitatif, yakni mendeskripsikan fakta, keadaan, dan fenomena yang terkait dengan dunia realitas di mana peristiwa tersebut diciptakan diciptakan. Hasil penelitian ini menemukan, bahwa media karya sastra masa sebelum kemerdekaan sebagai alat yang efektif untuk memberikan penyadaran kepada pembaca supaya rakyat memahami tentang kondisi sosial, ekonomi, dan politik yang terjadi di Hindia Belanda.
\end{abstract}

Kata kunci: rasa merdika; propaganda politik; tokoh utama; Hindia Belanda

\begin{abstract}
This research wants to see the political propaganda carried out by Soedjanmo, Sastro and Soedarmo figures in the novel Rasa Merdika by Soemantri. The political propaganda conveyed by the figure was about capitalism, poverty, and government policies that harm the people. This research method uses descriptive qualitative method, which describes the facts, circumstances, and phenomena associated with the world of reality in which the event was created. The results of this study found that the media of literary works before independence as an effective tool to provide awareness to readers so that people understand about the social, economic, and political conditions that occur in the Dutch East Indies.
\end{abstract}

Keywords: rasa merdika; political propaganda; main characters; the Dutch East Indies

\section{PENDAHULUAN}

Rakyat Hindia Belanda pada masa kolonialisasi yang dilakukan oleh pemerintah Belanda merupakan sebuah bangsa yang mempunyai sitem feodal di dalam kehidupan masyarakatnya. Kehidupan feodal ini terlihat jelas dalam keseharian masyarakat di Jawa dengan perbedaan kelas sosial dan tradisi yang digunakan. Rakyat pribumi di Jawa terbagi dalam dua kelas sosial, yaitu kelas priyayi dan kelas kromo (Sulton, 2015; Yuliati, 2000). Dari kedua golongan ini terdapat perbedaan yang nyata, ibarat antara kelas kapitalis dan kelas buruh.

Pihak penjajah kemudian memanfaatkan perbedaan kelas sosial ini dengan cara semakin memperkuat kerjanya untuk kepentingan pribadi. Pemerintah kolonial semakin banyak membantu kalangan kelas priyayi yang bermental penakut dan penjilat sebagai perpanjangan tangan mereka. Sedangkan rakyat Hindia Belanda yang berasal dari kelas kromo semakin tersiksa dan sengsara baik secara tenaga maupun ekonomi dengan cara memberikan upah kerja yang murah, dan penyewaan paksa lahan-lahan yang menjadi garapannya (Sulton, 2020).

Dalam situasi dan kondisi seperti itu, rakyat pribumi terpelajar dan orang Belanda sosialis yang mengetahui kondisi rakyat yang semakin sengsara menggugah kesadaran untuk memberontak atau melawan pihak pemerintah kolonial Hindia Belanda dan para pemodal. Bentuk perlawanan tersebut dilakukan dengan 
cara pemogokan menuntut kesejahteraan buruh dan melakukan propaganda kepada masyarakat luas. Kaum kolonialis Belanda maupun kaum aristokrat pribumi menjadi sasaran sindiran dan ejekan dalam pidato dan tulisan sebagian dari produk-produk awal 'pelainan' kolonial (Tickell, 2008). Sindiran dilaksanakan baik dalam bentuk vergadering, serikat-serikat buruh, penyebaran media surat kabar, karya sastra, dan dan seni pertunjukan.

Pada tahun 1920-an peran karya sastra memperoleh posisi sebagai media yang ampuh untuk mendidik kaum buruh rendahan pada saat itu. Menurut Sapardi Djoko Damono, bahwa novel-novel pendek yang ditulis di awal perkembangan sastra modern kita umumnya dinyatakan berdasarkan pada peristiwa yang pernah terjadi, terutama sekali yang pernah menghiasi halaman-halaman surat kabar dan menjadi masalah besar di pengadilan (Damono, 1999). Para pengarang kita zaman itu umumnya merasa perlu menegaskan bahwa fiksi yang mereka susun itu berdasarkan fakta, bahwa cerita mereka itu landasannya adalah berita. Novel Rasa Merdika karya Soemantri terbit tahun 1924 adalah sebagian kecil sampel rangsangan kepada kaum kromo untuk Rakyat Hindia waktu itu. Di dalamnya memuat teks propaganda, perlawanan, sekaligus pemberontakan berupa perdebatan antar tokohtokohnya berupa ideologi internasionalisme proletariat dan ide-ide politik. Ini diharapkan oleh pengarang, yaitu Soemantri ingin membentuk kesadaran permaneh pada kondisi yang dialaminya (Soemantri, 1924). Mengamati kejadian-kejadian sosial dan politik, menilai singnifikansi dan pengaruh kehidupan mereka terhadap kemajuan bangsa, terutama menyakinkan mengusir kekuasaan Belanda. Di samping itu, untuk pemahaman kepada kaum buruh mengenai hubunganhubungan produksi kapitalisme.

Cermin pemberontakan berupa propaganda yang terdapat dalam novel Rasa Merdika dilakukan dengan lisan, ceramah, dan dialog. Target propagandis (tokoh central) dari semua golongan, terutama rakyat miskin (kromo) karena masyarakat kromo mempunyai banyak harapan akan hadirnya sebuah kehidupan yang ideal dalam hidupnya. Saat mendengarkan ceramah atau dialog ideologi yang ditawarkan oleh sang propagandis, audien (tokoh pembantu) tanpa harus berfikir mendalam, meraka dengan senang hati menerimanya. Apalagi bila menyangkut pengangkatan dan pembahasan isu yang terkait dengan kehidupan rakyat menengah ke bawah, masyarakat atau komunikan akan mudah dirayu dan terlena dengan semua pengetahuan yang sudah disampaikan.

Permasalahan yang paling sering diangkat sebagai tema propaganda adalah persoalan kemiskinan rakyat pribumi dan ketidakadilan pemerintah yang dilandasi oleh faktor ekonomi. Begitu pula masalah kelas sosial dan penghisapan yang dilakukan oleh pemilik modal yang selalu bertindak sewenang-wenang terhadap rakyat jelata karena mereka mendapatkan perlindungan secara buruk oleh sistem pemerintah, padahal pihak atasan seperti kepala desa dan carik dipilih oleh rakyat dengan harapan ada perlindungan akan kondisinya tetapi, malah sebaliknya. Para oknum ini memaksa lahan-lahan rakyat untuk menyerahkan sawah garapan untuk ditanami tebu.

\section{METODE}

Metode penelitian ini menggunakan metode deskriptif kualitatif, yakni mendeskripsikan fakta, keadaan, dan fenomena yang terkait dengan dunia realitas. Hal ini menitikberatkan hubungan antar fenomena sejarah pada masa karya itu diciptakan. Propaganda dalam fiksi yang dilakukan Soedjanmo, Sastro, dan Soedarmo sebagai alat pembacaan strategi perlawanan dan dan pemberontakan rakyat Hindia Belanda. Sastra dari kaum pergerakan secara tidak langsung sebagai alat propaganda kepada pembaca umum dengan harapan penyadaran permanen.

Tahap kerja analisis deskriptif kualitatif untuk melihat novel Rasa Merdika dari berbagai aspek materi pendukung yang menyangkut sejarah Hindia Belanda dan propaganda politik. Santosa Sastropoetro, menjelaskan bahwa propaganda merupakan proses penyampaian pesan secara persuasif dari komunikator kepada komunikan dengan tujuan khusus, yaitu perubahan pada diri komunikan sesuai dengan kehendak komunikator . Dengan demikian, propaganda sebagai bentuk penyebaran pesan yang diharapkan dapat mengubah sikap, pandangan, pendapat dan 
tingkah laku dari komunikan sesuai dengan pola yang ditetapkan oleh komunikan.

Dalam novel Rasa Merdika lebih bersifat persuasif propaganda. Persuasif propaganda jenis ini menggunakan metode penyampaian pesan-pesan yang menimbulkan rasa tertarik sehingga target propaganda senang dan rela melakukan sesuatu (Shoelhi, 2012: 43). Ketertarikan itu bisa berupa sikap keleluasaan berfikir dan sikap saling membantu yang ditimbulkan dari ide propaganda yang disampaikan oleh propagandis, seperti sikap Tuan Chef yang menyamaratakan status di tempat kerja dan memberikan kesejahteraan buruh dengan cukup.

Metode persuasif dikatakan sebagai pendekatan yang membaginya dalam dua bagian, yakni perancangan komunikasi persuasif dan penahapan komunikasi persuasif - Perancangan komunikasi persuasif adalah sebuah perancangan yang dilakukan berdasarkan komponen-komponen komunikasi, yang meliputi komunikator, pesan, media, komunikan. Sedangkan penahapan komunikasi persuasif ditunjukkan sikap sang propagandis, seperti keramahan, kesederhanaan, ketenangan, ketulusan, kesungguhan, dan kepercayaan diri karena komunikasi tidak sebatas gaya bicara yang menarik dengan kata-kata yang merangsang. Penampilan yang menyenagkan, simpatik, dan menyakinkan ketika menghadapi mitra dialog sangat dianjurkan.

\section{PEMBAHASAN}

Pembahasan pemberontakan, kritik, dan propaganda tidak pernah lepas dari soal kemiskinan dan kesengsaraan masyarakat Hindia Belanda, seperti yang terjadi dalam kegelisahan Soedjanmo, tokoh utama. Propaganda di tengah-tengan cerita yang dilakukan Sastro dan Soedarmo dianggap sebagai solusi atas pertanyaan atau bayangan yang menghantui Soedjanmo selama ini.

\section{Propaganda Soedjanmo}

Soedjanmo (Sujanmo) adalah tokoh utama dalam novel Rasa Mardika. Pemuda berusia 18 tahun yang baru lulus dari sekolah. Kata Soejanmo terdiri dari akar kata $s u$ yang artinya "baik" dan janmo berarti "manusia". Sosok Sodjanmo sebagai orang yang baik budi, berbadan tegap serta sehat, perkataannya sopan-santun, tetapi berhati keras. Bey Soemo menilai Soedjanmo sebagai anak yang berkulit hitam manis yang berseri-seri.

Propaganda Soedjanmo hanyalah berupa jawaban atas alasan minta diberhentikan bekerja. Soedjanmo sempat khawatir kalau Vlammenhart bakal marah kepadanya karena mengungkapkan alasan-alasan untuk berhenti bekerja. Tapi alasan Soedjanmo inilah membikin pengetahuan baru bagi Vlammenhart, membukakan wawasan yang lebih kontekstual dan bersifat meyakinkan.

Propaganda Soedjanmo ini masuk dalam tiga unsur penting pada komunikasi persuasif ditinjau dari komponen pesan, yaitu pesan harus menarik perhatian, menyentuh perasaan, dan mampu memberikan keyakinan. Bahanbahan yang menarik perhatian bisa berupa gerakan yang berkaitan dengan sesuatu yang sudah dikenal (hal-hal konkret) atau sesuatu yang berhubungan erat dengan kepentingan masyarakat. Pada akhirnya dapat menyentuh perasaan melalui penggunaan daya tarik motif yang sangat relevan. Aspek ini untuk meyakinkan komunikan agar argumentasi sang propagandis tidak terbantahkan.

Sifat propaganda lebih sederhana, cukup perdebatan antara Soedjanmo dan Vlammenhart, tetapi diakhir dialog keduanya, Soedjanmo mampu menarik simpati Vlammenhart untuk meyakinkan.

"Ja.....ja.....bilang sadja teroes terang! Barang kali engkau tidak seneng kalau saja minta dihormati lain orang boekan?" menegor kata toean Vlammenhart.

"Benar, toean."

"Nau, sih....boekankah soedah seharoesnja dalem doenia ini siapa jang rendah menghormati jang tinggi?"

"Itoepoen boleh dikata demikian, bagi ini waktoe; tapi menoeroet pemandengan saja hal itoe tidak seharoesnja, karena segala manoesia itoe sesoenggoehnja sama sadja" (Soemantri, 1924:27).

Vlammenhart menegur atau mendugaduga. Barangkali ketidaksukaan Soedjanmo menjadi magang akibat kebencian melihat Vlammenhart dihormati, disembah-sembah 
dengan orang lain. Soedjanmo membenarkan dugaan Vlammenhart, bahwa dia tidak suka melihat adat sembah jongkok pada atasan karena pada dasarnya manusia itu sama saja. Namun Vlammenhart membantah, seharusnya manusia di dunia ini orang yang derajatnya rendah harus menghormati kepada orang yang derajatnya lebih tinggi.

Soedjanmo berusaha meyakinkan dan membantah pemikiran Vlammenhart. Soedjanmo kembali menanyakan balik kepada Vlammenhart tentang sebabnya orang bisa menjadi miskin dan rendah. Vlammenhart punya alasan kalau sebab-sebab dari kemiskinan adalah sudah takdir dari Tuhan. Soedjanmo kembali menyangkal Vlammenhart kalau dalam hal ini, soal kemiskinan Tuhan tidak akan ikut campur. Sesungguhnya hasil semua pekerjaan di dunia ini mengalir kepada orang-orang yang mempunyai modal. Buruh sebagai kulinya dianggap rendah derajatnya, sehingga orang yang mempunyai modal timbul nafsu pengharapan untuk minta dihormati.

Hal ini, belum membuat Vlammenhart yakin karena dalam pikirannya di dunia terdapat dua golongan, yaitu golongan kaya (orang yang mempunyai modal) dan golongan miskin (buruh bagi para pemodal). Soedjanmo menjelaskan kepada Vlammenhart, bahwa adanya kekayaan dan kemiskinan akibat dari tidak samanya pembagian hasil. Seumpama pembagian di dunia ini bisa dibuat sama rata, tentu tidak ada kemiskinan dan nafsu minta dihormati itu akan hilang.

".....kemiskinan dan kekajaan itoe terbitnja dari tidak samanja pembagian hasil. Kalau sadja pembagian hasil di doenia bisa dibikin sama rata tentoe tidak ada kemiskinan, dan dengen begitoe nafsoe kehormatan jang loear biasa itoe djadi hilang" (Soemantri, 1924: 28)

Vlammenhart semakin penasaran terhadap pengetahuan Soedjanmo yang sangat luas. Propaganda Soedjanmo dibuktikan dengan beberapa contoh dan kawasan realitas latar tempat sebab sumber-sumber kemiskinan, agar Vlammenhart pikirannya terbuka dan merubah sikap keseharian di kantornya. Soedjanmo memberikan contoh di Solo dan Yogyakarta sebagai kawasan yang feodalistik perpanjangan tangan pemerintah Belanda.

Pandangan seperti itu, telah menjadi pembicaraan dan kritik keras oleh tokoh yang anti feodal kolonialis Belanda, salah satunya adalah Tjipto Mangoenkoesoemo. Dalam surat kabar Panggoegah, 16 Juni 1919, Tjipto menulis bahwa Amangkurat II beserta keturunannya adalah budak feodal kolonialisme Belanda. Tjipto melanjutkan kampanye anti raja melalui rapat-rapat Insulinde, Volksraad, dan tentu saja via Penggoegah hingga edisi Oktober 1919.

"Tak bisa disangkal lagi, doea keradjaan memangsa pendoedoeknja, bahwa mereka tak bisa bertahan hidoep tanpa menghisap rakjat sampai kesoemsoemnja, tanpa melonggarken pajak jang begitoe mentjekik...saja merasa bahwa segala kemewahan itoe biajanja haroes dibajar dari kantong orang kromo...pada achirnya orang kromo itulah jang haroes 'menghidoepi' radja."

Dua kerajaan yang dimaksud Tjipto adalah Yogyakarta dan Solo. Dari tulisan itulan Tjipto banyak ditentang oleh kalangan yang pro dengan abdi dalem. Iswara $\mathrm{N}$ Raditya, menambahkan aksi Tjipto tersebut memantik murka kubu pro-kerajaan, yang dilakonkan para priyayi Boedi Oetomo (BO) serta kalangan abdi dalem lainnya, termasuk Samanhoedi, pendiri Sarikat Islam, juga Martodharsono melalui surat kabar Darma Kendha dan Djawi Hiswara (Tanah Air Bahasa Jejak Pers Indonesia, 2007: 42). Bersepakatlah bumi feodalisme Jawa untuk membentuk Komite Anti-Tjipto. Tapi Tjipto semakin "menggila", mengritisi raja dengan berbagai cara. Bahkan, di masa sebelumnya, pada 1909, Tjipto dengan sengaja naik kendaraan di depan Kraton Sunan di Surakarta untuk menunjukkan ketidaksukaannya terhadap kalangan aristokrat kerajaan.

Gambaran sejarah yang ada pada saat itu tercerminkan dalam karya sastra. Sastra sebagai dokumen sosial budaya yang terjadi. Sehingga paparan yang dicontohkan Soedjanmo itulah, pada akhirnya membuat Vlammenhart meyakini dan membukakan pengetahuannya, 
bahwa sebab dari kemiskinan adalah pembagian hasil yang tidak merata. Begitu juga Hormat sembah-sembah datangnya dari status kepangkatan manusia. Orang yang lebih rendah akan menyembah yang atas, dan yang atas itu akan menyembah pula kepada orang yang lebih atas lagi, begitu seterusnya.

Vlammenhart yang pada permulaan berwajah menakutkan, berwatak keras, dan suka memaki-maki pegawainya kini nampak berbeda di hadapan Soedjanmo. Propaganda yang dilontarkan Soedjanmo dianggap berhasil. Komunikan menerima atau tunduk, yakni menerima posisi baru setidak-tidaknya pada taraf verbal. Keberhasilan Soedjanmo ini dinilai karena kemampuan mempengaruhi Vlammenhart menggunakan topik peristiwa sejarah, pengalaman pribadi, dan disertai dengan kejadian-kejadian aktual yang mendukung.

Setelah mendapatkan izin dari Vlammenhart untuk berhenti bekerja, Soedjanmo memulai dengan pengembaraan di hari Minggu. Selama di perjalanan naik kereta api, Soedjanmo berkenalan dengan Kromotjiloko, dia adalah korban feodalisme dan kerakusan kapitalis dalam merebut lahan garapannya. Dari Kromotjiloko pula Soedjanmo membentuk propaganda, namun pesan propaganda yang diutarakan bersifat dialong, memberikan keyakinan, pengetahuan, dan pengharapan perubahan. Ternyata cara Soedjanmo mampu menarik simpati Kromotjiloko.

Pada awalnya Soedjanmo merasa tersinggung, dianggapnya tidak pantas kalau dipanggil Kromotjiloko dengan sebutan "den". Kromotjiloko berpikiran kalau umumnya di desa tempat Kromotjiloko tinggal, anak seorang pegawai onderdistrict harus dipanggil raden bagus, kalau tidak maka akan kena marah. Soedjanmo meyakinkan Kromotjiloko, menjelaskan bahwa dasar kata dari "den" berasal dari "raden", bahasa Jawa "rah" dan "hadi" artinya darah yang baik. Maksudnya darah yang baik itu sudah tentu biak budi dan wataknya seseorang. Tapi orang-orang sekarang menganggap "raden" sebagai nama kebesaran, sehingga makna yang sebenarnya dari perkataan itu sudah hilang.

"Nah! Bapak haroes tahoe djoega

bahwa Raden itoelah asalnja dari bahasa Djawa Rah-hadi, ertinja darah jang baik. Maksoednja darah baik itoe soedah tentoe djoega berarti orang-orang jang baik boedi dan wataknja. Tetapi orang-orang sekarang, seboetan jang demikian itoe olehnja dianggep sebagai kebesaran, hingga maksoednja perkataan itoe jang sesoenggoehnja laloe djadi linjab" (Soemantri, 1924: 36).

Kromotjiloko semakin tercengang, menambahkan semakin penasaran maksud dari Soedjanmo. Kepenasaran ini membuat Kromotjiloko bertanya tentang anggapan di dunia ada dua darah baik dan darah buruk. Soedjanmo kembali megatakan, bahwa di dunia ada orang-orang yang mengaku dirinya bangsawan dan raja-raja. Mereka itu dulunya orang biasa-biasa saja, berhubung dia dianggap orang yang mampu menjadi pemimpin oleh rakyatnya, maka sebagai tanda terima kasih masyarakat menganggap dirinya lebih tinggi dari yang lain, lalu dipakailah sebutan "raden". Lama kelamaan sebutan itu dianggap benar untuk memanggil orang sekarang yang kepangkatannya lebih tinggi. Orang dahulu memang sudah pantas dipanggil dengan sebutan raden karena sudah bisa memakainya, menjadi penolong rakyat dan rajin membela kehidupan rakyat, sehingga mereka pantas disebut sebagai darah yang baik.

Kromotjiloko terlihat antusias menyimak propaganda Soedjanmo, membenarkan perkataannya sebab apa yang dilihat Kromotjiloko di penduduk desa Lapangmanis benar kenyataannya. Selain itu, bisa dilihat pada saat berkunjung ke rumah bangsawan melihat seorang bangsawan yang diiringi memakai cara kebesaran padahal tidak pernah melindungi dan memberikan pertolongan kepada penduduk malah setiap hari hanya bersenang-senang di rumah dengan para dayangnya. Hal yang demikian Soedjanmo mengatakan tidak sepatutnya mereka-mereka itu dipanggil dengan sebutan raden, raden mas, ario, dan sebagainya.

Sampai di sini, propaganda politik Soedjanmo dirasa lebih efisien dan berhasil untuk mempengaruhi komunikan, baik Vlammenhart maupun Kromotjiloko keduanya 
sama-sama takluk. Keberhasilan propaganda Soedjanmo dinilai sebagai akibat dari penggambaran konsep realitas yang dimunculkan, contoh kasus-kasus dan fenomena dijadikan teknik yang ampun untuk mempengaruhi lawan bicaranya. Usaha demikian, bisa disebut pembentengan dari argumentasi komunikan melalui perdebatanperdebatan selama proses menawarkan gagasan.

Idealisme yang menjadi dasar propaganda Soedjanmo tidak jauh dari persoalan adat-adat kuno yang masih dipertahankan di masyarakat dan sebab-sebab dari timbulnya kemiskinan. Pada kasus Vlammenhart, Soedjanmo mengkritik soal adat sembah jongkok yang menurutnya dasar dari manusia itu sama saja. Selain adat sembah, perkara kemiskinan menjadi bahan propaganda Soedjanmo, dalam hal ini Soedjanmo melihat sebab-sebab dari kemiskinan adalah masalah pembagian hasil yang tidak merata seandainya sistem ini diterapkan maka tidak ada kemiskinan, dan nafsu rasa ingin dihormati itu akan hilang. Selain itu, propaganda Soedjanmo kepada Kromotjiloko juga tidak jauh membicarakan persoalan adat. Pemanggilan nama "den" menjadi bahan propaganda, karena dasar "den" atau "raden" bermakna darah yang baik. Nama ini diperuntukkan untuk kalangan raja-raja yang benar-benar berhati baik, suka menolong, dan melindungi masyarakatnya.

\section{Propaganda Sastro}

Sastro sebagai tokoh yang mengenalkan ideologi-ideologi internasionalisme kepada Soedjanmo. Pergerakannya sangat dekat dengan tokoh propagandis, seperti Soedarmo dari kota S. Tapi tokoh Sastro tidak nampak digambarkan sebagai orang yang berwatak keras. Dari dialog antar tokoh terlihat kalau Sastro orang yang berpendidikan dan mudah bergaul dengan siapapun, peramah, dan pandai menjalin komunikasi.

Perkenalan Sastro dengan Soedjanmo bermula di firma Tuan Chef. Sastro sebagai asisten Tuan Chef melakukan tes menghitung rekening-rekening courant dan giro dari Javabank untuk menguji kemampuan Soedjanmo sebelum diterima dalam kantor dagang. Setelah dikerjakan sesuai waktu yang ditentukan, Tuan Chef mengambil semua kertas dan buku-buku yang dikerjakan Soedjanmo. Dengan teliti, Tuan Chef melihat-lihat hasil pekerjaan Soedjanmo, tidak begitu lama Tuan Chef memberikan selamat kepada Soedjanmo untuk diterima bekerja di kantor, ditempatkan dalam afdeling boekhouding. Karena Soedjanmo sebagai pegawai baru di kantor itu, maka Tuan Chef menggaji pertama dengan $f$ $125,-/$ bulan. Uang sebesar itu dirasa Soedjanmo sangat besar, sehingga dengan bangga Soedjanmo kegirangan. Mukanya yang tadinya terlihat asam, sekarang berbalik menjadi berseri-seri.

Tuan Chef memanggil Sastro, bermaksud agar keluarga Sastro bersedia untuk Soedjanmo sementara waktu tinggal di rumahnya. Dengan tidak keberatan, Sastro menerima usulan Tuan Chef. Ketika kantor sudah tutup, Sastro dan Soedjanmo pulang jalan kaki. Sepanjang jalan mereka berdua bercakap-cakap untuk saling mengenalkan secara pribadi. Memang rumah sewa Sastro tidak jauh dari kantor tempat dia bekerja, di sebuah kampung yang sederhana. Rumah itu tidak besar, hanya terdiri dari empat kamar, dan di halaman rumah ada bermacammacam bungan wamar ditanam di pot.

Dari rumah Sastro itu, Soedjanmo akhirnya kenal dengan istrinya, $\mathrm{Nji}$ Endang. Keterbukaan Nji Endang ini terlontar melalui perkataanya bahwa banyak persaudaraan maka makin lebar pula pemandangan. Ketiganya berbicara rupa-rupa perkara, sesekali saling tertawa. Pendangan berfikir mereka kelihatan cocok, Nji Endang juga punya pendapat kalau adat-adat yang diceritakan Soedjanmo sudah tidak patut digunakan. Watak-watak yang seperti itu dulunya dijalankan oleh kaum feodal.

Pada waktu sore hari, Sastro Nji Endang, dan Soedjanmo berduduk santai menikmati teh hangat. Mereka membicarakan tentang agenda vergadering yang akan berlangsung besuk pagi. Tema yang yang akan dibicarakan dalam acara itu mengenai faham internasionalisme. Ketiga orang tersebut berencana akan mengikuti vergadering. Momen inilah yang ditunggutunggu Soedjanmo karena mereka tidak mengerti apa maksud dari internasionalisme. Sastro sebagai jurnalis di surat kabar gerakan buruh sering mendengar istilah yang terkait ideologi internasionalisme, sehingga di waktu sore itu terjadi semacam propaganda Sastro 
atau memberi keyakinan kepada Soedjanmo dan Nji Endang.

Nji Endang semakin rasa ingin tahu, begitu juga Soedjanmo. Dari sini, kembali Sastro menjelaskan panjang lebar yang dimaksudkan perkataan sebelumnya.

"Ja.....tetapi kanda loepa. Dari pada bangsa-bangsa jang kenda katakan itoe tadi dari golongan jang mana?" menjamboeng $\mathrm{Nji}$ Endang pada lakinja seolah-olah ia memperingatken.

"Soedah tentoe dari pada bangsabangsa jang sama jelasnja. Sebab dari pada beberapa golongan bangsa jang ada doea matjem kelas, jaitoe kelas jang memerintah dan kelas jang terperintah" (Soemantri, 1924: 64).

Persatuan faham internasionalisme untuk menghilangkan kelas kapitalis dan kelas buruh. Dengan bersatunya negara-negara maka peperangan dalam dunia tidak akan terjadi. Peperangan dianggap Sastro hanyalah untuk menambah kejayaan dari pada orang-orang yang mempunyai pejabat tinggi, dan kelas rendah ibarat sebagai alat untuk melakukan peperangan.

Peperangan di dunia, Sastro berbendapat sebatas masalah makan sebab tidak ada orang yang bisa senang hidupnya dan tidak ada tempat yang aman melainkan serba kecukupan dalam hidupnya. Sudah banyak kejadiankejadian di dunia ini yang begitu ribet hingga banyak menumpahkan darah manusia. Soedjanmo dan Nji Endang, menyimak dengan serius kalimat demi kalimat yang diucapkan Sastro, sesekali Nji Endang menanggapi dan balik bertanya apa yang menjadi kesulitan dari keterangan Sastro.

Sastro balik menyinggung buku sejarah, sekedar meyakinkan pada Nji Endang dan Soedjanmo, yang menjadi target propaganda. Sastro mengatakan, dalam buku "Riwajat Pergaoelan Manoesia" sudah diterangkan bahwa dahulu kejadian macam sekarang tidak ada (penindasan). Namun setelah penghasilan dipegang oleh segelintir para pemodal kesengsaraan dan kemiskinan semakin merajalela. Sastro mengkritisi kalau yang menjadi persoalan rumitnya kehidupan sekarang ini adalah "hak diri", seumpama hak yang semacam itu dilenyapkan, diubah menjadi hak persamaan maka otomatis kesenjangan akan hilang dengan sendirinya. Hak diri ini akan menyebabkan perkara yang lebih luas, seperti halnya pertumpahan darah rakyat ke muka bumi.

Nji Endang mulai memprotes pemaparan Sastro, dianggapnya yang dilontarkan adalah perkara besar bukan lagi masalah sekeliling di dalam kehidupannya. Kembali Sastro memberikan contoh petani yang mencangkul sawahnya, satu atau dua bauw lantaran itulah yang bisa dikerjakan oleh petani, ini yang dimaksud hak sendiri.

Tetapi seorang kaoem tani bisa bekerdja sendiri oentoek menjangkoel sawahnja jang hanja satoe doea bahoe saja. Lantaran ia bisa bekerdja begitoe maka ia anggep bahwa itoe haknja sendiri (Soemantri, 1924: 67).

Selama Sastro berkata begitu, Soedjanmo hanya senantiasa duduk diam sambil pikirannya memahami betul-betul. Nji Endang tidak terima dengan apa yang dikatakan Sastro, yang ada dalam pemahaman Nji Endang selama ini kalau hak diri hanya dikerjakan selalu sendiri, bagaimana halnya seandainya itu sebuah pabrik apa selalu cukup dikerjakan dengan satu atau dua orang saja. Sastro berbalik memberikan pengertian Nji Endang, kalau barang yang dihasilkan oleh pabrik adalah kumpulan dari buah tangan kaum buruh, selanjutnya keuntungannya buah tangan itu dibagi sama rata bukan hanya dinikmati oleh segelintir orang.

"Tetapi hasilnja atau lebih
gampang saja bilang sadja
oentoengnja dari boeah tangan
sekalian orang jang bekerdja itoe
boekannja oentoek mereka
maar.....digaroek oleh toean
paberik" (Soemantri, 1924:67)

Nji Endang dengan sedikit tertawa mengelak apa yang dilontarkan Soedjanmo, dianggapnya memang sudah tentu haknya pemodal karena dia yang membangun alat-alat pendukung produksi. 
Sastro kembali melancarkan propaganda untuk meyakinkan Nji Endang yang dirasa tetap belum mengerti.

"Dinda haroes bahwa kaoem boeroeh itoe selamanja memang sama rata. Dari itoe soeka atau tidak kaoem boeroeh mesti setoedjoe dengan datengnja djaman persamaan, lantaran sebagian tadi saja kataken, maka hatsil (produstie) dari pekerjaan boeroeh jang dikerdjaken dari sehari kesehari itoe goenanja oentoek hidoep bersama. Goela jang diperboeat oleh boeroeh dalem paberik tidak bisa dihabisken oleh boeroehnja sendiri, atau oleh toean paberik sendiri, tetapi dirasaken segenap manoesia. Tetapi......oentoengnja dari kehasilan itoelah jang tidak dirasaken oleh segenap manoesia, hanjalah oentoek toean paberik" (Soemantri, 1924:68).

Sastro menekankan kalau buruh selamanya harus sama rata. Pada saat datangnya zaman suka atau tidak suka kaum buruh harus menerima persamaan, dan dari hasil yang dikerjakan setiap hari itu fungsinya untuk kebutuhan bersama. Seperti halnya pabrik gula, keuntungannya tidak dirasakan oleh kaum buruh atau kaum pemodal sendiri tetapi sepatutnya dirasakan oleh segenap manusia. Dari sini Nji Endang mulai memahami apa yang dimaksud Sastro.

Untuk sekedar mempertegas, Sastro manambahkan bahwa di pabrik terbagi dalam beberapa golongan untuk mengerjakan satu jenis barang, ada yang membikin sekrup, ada yang membuat tali, dan ada yang membuat paku. Dari golongan itu terbagi lagi berdasarkan tingkat kepandainnya dalam melakukan pekerjaan. Hal senada juga terjadi dalam pergaulan kehidupan sehari-hari, misalnya ada orang yang menyelidiki binatangbinatang untuk mengetahui waktu datangnya hujan, tukang menghukum, tukang membuat wat, tukang menghitung, dan sebagainya.

Soedjanmo dan Nji Endang sedikit terbuka dasar dari pengertian internasionalisme. Tidak menyangkut contoh besarnya saja yang dijelaskan Sastro tetapi hal-hal sekelilingnya dijadikan dasar contoh untuk meyakinnya keduanya. Stretegi pengambilan contoh dengan ide dasar pengetahuan tersebut sebagai suatu kesatuan yang utuh dan korelasi. Oleh sebab itu, teknik penataan pesan seperti ini William Albig menyebutnya dengan istilah icing technique atau teknik tataan. Teknik sebagai seni menata pesan dengan imbauan emosional sedemikian rupa sehingga menarik perhatian komunikan hingga terdorong untuk mencerna pesan. Pesan yang disusun sedemikian rupa, enak didengar sehingga komunikan termotivasi untuk menerima pesan sebagaimana disarankan.

\section{Propaganda Soedarmo}

Soedarmo (Sudarmo) dapat didefinisikan asal kata su yang bermakna "baik" dan darmo berarti "perbuatan". Soedarmo adalah tokoh propagandis dari kota S. Ideologinya berhaluan humanisme, kemakmuran dan kerukunan manusia sebagai tujuan propaganda yang hendak disampaikan. Sosok Soedarmo muncul dalam novel Rasa Merdika sebagai tokoh utama propagandis, penyampai ideologi. Pada pagi hari, Soedarmo memberikan ceramah di kota P. Peserta yang ingin mendengarkan ceramah Soedjanmo sangat banyak. Waktu itu Soedarmo duduk di samping meja Bestuur.

Peserta vergadering yang datang sangat banyak, bahkan sampai berjubel tidak mendapatkan tempat duduk. Para peserta yang datang bukan saja dari kelas ekonomi rendah tapi ada juga dari kaum ekonomi menengah, Soepini adalah salah satu contohnya. Meskipun Soepini dari keluarga kaya dan berpendidikan M.U.L.O namun dia suka mendengarkan voordracht (ceramah) yang berguna dan baik untuk umum, dengan maksud untuk menambah pengetahuannya. Mereka menyatu atas visi dan misi yang sama untuk kepentingan umum di bawah sinar gas pompa sore itu. Sastro berperan sebagai lid komite yang akan membuka persidangan.

Sebelum ceramah Soedarmo dibuka voorzitter meberikan aba-aba bahwa acara akan dimulai, kemudian memberikan tata cara berlangsungnya vergadering. Soedarmo mulai berdiri dengan roman muka yang sedikit tersenyum. Memberikan tanda bahwa Soedarmo adalah sosok yang tegas. Soedarmo 
menyampaikan ceramah bertajuk internasionalisme yang saat ini (konteks novel) masih menjadi pembicaraan orang banyak lantaran belum mengerti maksudnya. Orangorang sudah mulai diam, satu sama lain kalau berbicara saling berbisik.

Soedarmo memulai perkataan tentang pentingnya voordracht tentang internasionalisme supaya anggapan-anggapan masyarakat tidak salah persepsi sebab tulisan di surat kabar ada yang menerangkan bahwa kaum internasionalis akan menjual bangsanya ke tangan lain bangsa. Memang benar di bumi ini terbagi menjadi beberapa golongan bangsa, dan terbagi pula menjadi bermacam-macam tanah kecil (vaderland) bagi masyarakat. Tetapi alatalat menghasilkan rakyat tersebut sudah tergenggam oleh pihak pemodal. Pedagang dari kapitalis mulai membuka (memaksa) tanah penduduk untuk menjadi pasar jajahannya, akibatnya vaderland menjadi musnah.

Kemadjoean kapitalisme sendiri dalem tiap-tiap tanah soedah mendorong pada segolongan dari bangsa di tempat itoe ke liang kemiskinan. Adapoen sebabnja jaitoe dari adanja hak diri, ertinja keoentoengan dari hatsil pekerdjaan kaoem boeroeh diakoei oleh si kaoem modal (Soemantri, 1924:77).

Penghisapan dari kaum kapital dijalankan terus-menerus, sehingga orang yang dulunya bisa hidup tentram di desa manjadi terusir dalam negerinya sendiri, mereka itu dikatakan sebagai orang-orang yang "merdeka" lari ke kota untuk menjual tenaganya. "Merdeka" berarti tidak mempunyai lahan garapan lagi, hanya bisa disuruh-suruh oleh majikannya. Orang-orang desa yang dulunya masih bisa menggarap sawah satu atau dua bauw dengan datangnya kapitalis membuat penduduk desa di bawah perintah pabrik. Kalau kondisi rakyat sudah jadi begini, pekerjaan seberat apapun dengan gaji yang murah akan dilakukan karena untuk menyambung hidup keluarganya.

Pemikiran propaganda yang dilontarkan Soedarmo di atas tentang keberadaan kapitalisme, yaitu datangnya pabrik gula sudah banyak dibahas para tokoh pergerakan dalam surat kabar waktu itu. Tjipto
Mangoenkoesoemo menulis dengan beraninya menentang keberadaan P.G bahwa "kita aken tinggal tetep melawan politie-politie yang aken menghadliri kita poenja hulshoudelijke vergadering, sebab.....dia tidak perloe ada di sitoe". Persoalan agraria ini mempengaruhi iklim pergerakan Sarekat Islam Semarang dan sekitarnya dalam tahun 1917-an dan menjadikan organisasi itu lebih revolusioner (Gie, 1999: 10). Kenyataan-kenyataan sosial yang mereka lihat, dengar dan alami, menggugah perasaan para tokoh organisasi itu. Ketidakpuasan umum, ketidakpercayaan pada niat baik pemerintah dan sebagainya, akhirnya membuah Sarekat Islam Semarang lebih revolusioner.

Soedarmo sebagai tokoh fiksi melakukan propaganda kepada masa, karesteristik vergadering, perlawanan, dan kesejahteraan buruh menjadi harapan mereka, rakyat Hindia Belanda. Nampak bahwa pemahaman relitas terekam dalam fiksi. Soedarmo dalam propaganda juga mengatakan, bahwa orangorang yang lahan garapannya sudah dirampas dianggapnya sudah tidak mempunyai tanah air, karena tanah air yang dicintainya tidak mempu memberikan makan dan kesejahteraan bagi anak dan isterinya.

Sastro memberikan contoh bekas tanah milik orang-orang desa yang mencintai tanah airnya. Tanah di pinggiran perkampungan banyak ditanami pohon bambu sebagai pagar desa agar keberhasilan dan kehidupan di dalam rakyat tidak mampu dirampas atau dirusak oleh orang dari desa lain. Meskipun dipagari, kekuatan kapitalisme tetap mampu menerobos pagar-pagar itu, dan dengan diam-diam orang desa itu akan terusir satu persatu untuk mencari kehidupan di kota-kota. Dengan demikian, majunya kapitalis ditandai dengan ramainya kota-kota dipenuhi oleh kaum proletar.

Karena paengaroeh imperialisme, orang-orang jang tergolong pada kasta proletar terpaksa lari dari negara ke lain-lain benoea oentoek mentjari makan sebab di negerinja mereka soedah tidak berpentjarian poela. Makin lama mereka tinggal dalem tempatnja jang baroe itoe, makin loepalah ia pada toempah darahnja jang pertama-tama. Djanangken ketjintaan pada tanah 
toempah darahnja, sedangken bahasanja sendiri poen ia soedah tidak mengenal (Soemantri, 1924:50).

Kutipan propaganda Soedarmo mengatakan, kalau akibat pengaruh dari imperialisme tersebut kaum proletar sama merantau ke lain tumpah darahnya berakibat melupakan pada kampung halamannya, bahkan bahasanya sendiri sudah lupa. Kaum kapitalis tidak mencintai tanah tumpah darahnya, hanya mencintai pada tanah yang bisa memberikan keuntungan padanya. Begitu sebaliknya, kaum buruh tidak mengerti tanah tumpah darah yang sesungguhnya, hanya mengerti tempat di mana mereka bisa mencari kehidupan.
Kasta boeroeh ini hanja bisa menaik deradjatnja bila dia soedah sadar dan soeka bersatoe dengen segenep bangsa-bangsa dalem doenia jang bersamaan nasibnja. Kita haroes melinjapken pikiran- pikiran koeno, jang meninggi- ninggiken "vaderland" dan kebangsaan, hingga bisa djadi "gila bangsa" jang achirnja moedah dipermainken oleh dipertoean, digiring ke medan peperangan diadoe sama lain manoesia jang sekelas dengen dia, padahal dia tidak mengerti apa maksoednja itoe (Soemantri, 1924:80-81).

Sastro juga memberikan solusi untuk mengangkat derajat kaum buruh dengan cara sadar untuk bersatu dengan bangsa-bangsa lain. Menghilangkan pikiran kuno, yang mengunggul-ngunggulkan wilayah atau bangsanya sendiri karena akibat dari nasionalisme ini akan dipermainkan oleh para pejabat dan pemodal untuk digiring ke dalam peperangan sesama kelas buruh. Dunia harus diselamatkan, dan untuk mencapai pada taraf seperti itu bangsa-bangsa harus dipersatukan, yaitu menjadi "bangsa dunia". Oleh karena itu, yang harus jadi tanah tumpah darahnya, yakni dunia yang dibagi ini. Kasta buruh dari berbagai bangsa-bangsa bersama menuntut perbaikan nasibnya "sama rata". Dari sinilah, harapan kasta buruh untuk mendapatkan keselamatan dunia baru dapat dicapai.

Selama mendengarkan ceramah Soedarmo di atas, masa tidak ada yang bergerak mondarmandir atau berbicara sendiri sehingga suara Soedarmo bisa ditangkap di ruangan itu oleh masa yang sangat banyak. Usai pemaparan ceramah, masa riuh bertepuk tangan menandakan kalau masa sangat antusias dan menyetujui ideologi internasionalisme. Beberapa dari korrespondent (wartawan) surat kabar mencatat apa yang menjadi voordract Soedarmo, akan menyiarkan untuk pemberitaan agar rakyat (pembaca) memahami pengertian internasionalisme.

Voorzitter mengetuk palu, pertanda paparan propaganda selesai dan dibuka dengan perdebatan atau pertanyaan. Abdulgani sebagai orang pertama yang bertanya sekaligus mendebat, disusul oleh Sariman. Mohamad Abdulgani dalam novel Rasa Merdika berperan sebagai orang yang mendebat Soedarmo. Dia perpendidikan santri dari pondok pesantren. Gagasan Soedarmo yang tidak disetujui Abdulgani adalah:

a. Abdulgani tidak setuju kalau akibat kemiskinan adalah karena kapitalisme;

b. Abdulgani berpendapat kalau semua yang terjadi di dunia ini adalah takdir Tuhan. Kaya dan miskin sebagai akibat dari usaha manusia. Orang miskin dinilai karena kehidupan yang boros, sedangkan orang kaya karena pandainya mengumpulkan uang;

c. Bangsa-bangsa dijadikan satu itu adalah mimpi. Karena agama kalau dijadikan satu akan campur aduk yang tidak sesuai dengan ajaran Nabi. Setiap negara mempunyai riwayat dan watak serta bahasa sendiri-sendiri;

d. Bangsa-bangsa di dunia ini kalau ada peperangan itu memang sudah benar, cerminan lelaki sesungguhnya dan itulah orang yang setia pada raja-raja;

e. Kalau bangsa-bangsa di dunia ini menjadi satu dengan orang-orang buruh maka akan terjadi keributan selama-lamanya karena umumnya orang buruh itu bodoh.

Sampai di situ Abdulgani akhirnya memberikan saran kepada Soedarmo, 
umumnya kepada peserta vergadering yang datang.

Kemenangannja satoe bagian jang begini tentoe membawa sengsara pada lain bagian poela. Oleh karena itoe seharoesnjalah antara doea golongan itoe tadi berdaja oepaja sadja mentjari tempat oentoek mempersatoeken keperloeannja masing-masing, tapi djangan dilenjapken salah satoenja (Soemantri, 1924:84)

Abdulgani berlatar belakang sebagai kyai, maka perdebatan yang disampaikan berdasarkan pandangan dasar-dasar dari agama. Secara garis besarnya antara golongan kapitalis tidak dapat dilenyapkan dari muka bumi. Antara kapitalis dan buruh seharusnya berjalan sesuai kepentingan masing-masing.

Setelah Abdulgani menyampaikan pesan di atas mimbar, giliran Sariman naik ke mimbar. Sariman memakai baju kebaya yang sudah lusuh dengan sarung yang tinggi beserta celana pendek yang kombor. Dia berbicara dalam bahasa Jawa dengan dialek yang lucu (vergadering menjadi "blegadering"), putusputus dan gugup sehingga setiap perkataan Sariman membuat orang jadi tertawa.

"Saja ini orang dari desa dan tidak pandai omong; tetapi karena saja poenja hati amat senang, dan setoedjo mendenger pembitjaraan toean itoe tadi, saja djadi soeka toeroet bitjara. Pendeknja karena saja tidak bisa omong pandjang, saja..........saja..........moepakat....... .....sama itoe omongan, soedahlah, sebab saja sendiri soedah sering lihat kenjataan dari hal perginja orang-orang dari saja poenja desa; malah-malah banjak jang masoek kontract Deli. Pendeknja saja moepakat dengen blegadering ini" (Soemantri, 1924:85).

Perkataan Sariman di atas sekedar apresiasi terhadap apa yang dijelaskan Soedarmo. Kalau diamati, sosok Sariman sebagai orang yang bodoh dan miskin dinilai dari pembicaraan dan penampilan. Pada saat turun dari mimbar, tingkahnya sangat lucu. Pencerita menggambarkan sebagai orang dari penduduk desa seperti yang dilukiskan Soedarmo dan minimnya pengetahuan. Dari tanggapan Sariman, setidaknya dia faham atas realitas yang sedang terjadi di desanya tentang kepergian para penduduk bahkan ada yang menjadi kontract Deli.

Dalam propaganda Sastro dijelaskan kalau penduduk desa banyak yang meninggalkan tanah tumpah darahnya untuk menjadi kuli contract. Pada Masa pemerintahan Hindia Belanda rakyat dari pulau Jawa yang ribuan jumlahnya itu pergi ke Deli, Sumatera Timur untuk menjadi kuli. Para buruh yang menjadi kuli kontrak pabrik tembakau di Deli mengalami penyiksaan oleh mandor ataupun tuan besar perkebunan menyebabkan mereka kehilangan harkat dan kebebasan. Kehidupan para kuli contract di Deli ditentukan berdasarkan kentongan bangun pagi, istirahat siang, tidur malam, dan sebagainya (Aulia, 20006: 73). Setiap kuli yang melakukan kesalahan akan mendapatkan cambuk, tendangan, dan pukulan. Seorang kuli wanita kalau tidak mau diajak seks oleh tuan asisten perkebunan akan dijemur dalam keadaan telanjang selama berhari-hari dari matahari terbit sampai terbenam. Para opas-opas pribumi mencambuki pinggulnya dengan tali sanggurdi. Belum puas melakukan itu, tuan opas menggosok kemaluannya dengan lada yang ditumbuk halus. Perempuan tambah meraung, teriak kesakitan.

Sariman yang dianggap orang yang tidak berpendidikan tinggi, mampu mengkritsi kondisi sosial yang terjadi di lingkungannya. Kuli kontrak di Deli, Sariman melihatnya sebagai suatu keterpaksaan, ada kemungkin Sariman mengetahui berdasarkan cerita yang berkembang atau hasil membaca dari surat kabar.

Selesai Abdulgani dan Sariman berbicara di mimbar, Soedarmo kembali naik mimbar untuk menjelaskan atas sanggahan Abdulgani dan pernyataan Sariman. Sangggahan Abdulgani ditanggapi Soedarmo dibagi menjadi lima bagian:

a. Dikatakan kemiskinan bukan dari kapitalisme. Soedarmo menilai hal ini dianggapnya sebagai suatu pikiran yang sesat. Kalau kemiskinan karena takdir Tuhan, Soedarmo menyebut Tuhan itu tidak adil. Manusia dilahirkan untuk mengatur pergaulan 
hidupnya agar aman dan tentram. Kapitalisme menetapkan adanya hak diri, dan karena hak diri inilah berakibat tidak adilnya pembagian hasil. Orang yang kaya akan semakin kaya dan orang yang miskin akan bertambah sengsara.

"Pendek, kalau kita memikir pergaoelan hidoep tetapi sekonjong-konjong laloe memikirken "Toehan" maka terang sekali jang pikiran itoe tidak teratoer. Dan lagi apabila orang memegangi "kodrat", boeat apa orang ichtiar?" (Soemantri, 1924:86)

Kodrat Tuhan dinilai Soedjanmo tidak bersangkutan dengan pergaulan hidup, kalau ada orang yang menganggap Tuhan itu ikut campur disebutnya sebagai suatu yang sangat keliru karena manusia perlu adanya ikhtiar (usaha).

b. Orang menjadi miskin lantaran hidup boros sedangkan yang kaya karena kepandaian dalam mengumpulkan uang. Soedarmo mengganggap pendapat tersebut adalah sesat. Kemiskinan bukan lantaran hidup boros, tetapi adanya pembagian hasil yang tidak seimbang. Pemikiran Abdulgani terlalu sempit, Soedarmo menyarankan untuk belajar bertahun lamanya agar bisa memahami tentang ragam kehidupan sebab-sebab kemiskinan dan kerakusan kapitalis.

"Kalau kemiskinan berhamboeran ini lantaran boros, apakah berdjoeta-djoeta kaoem miskin itoe, boros semoea? Boeat menerangken ini sampai djelas, kata Soedramo toean Abdulgani haroes beladjar berboelan-boelan malah bertahoen-tahoen lamanja. Kalau pemandengannja hanja disempitken sadja, soedah tentoelah orang djadi tersesat sampai begitoe djaoeh. Bagian jang sedikit oentoek segenap kasta proletar, sedeng bagian jang banjak oentoek kasta modal jang sedikit djoemlahnja"

(Soemantri, 1924:86).

c. Kalau orang perang dikata Sah. Soedarmo memandang peperangan, tergantung kepentingan tiap-tiap golongan. Peperangan dahulu dengan peperangan sekarang sudah berbeda. Dahulu orang berperang untuk keperluan setiap orang di dalam golongannya.

"Dalem peperangan sekarang si proletar jang digiring kelapang pemotongan manoesia itoe ta tahoe apa sebab dan boeatnja ia bertaroeh njawa. Semoea keuntungan di garoek oleh kasta modal, tetapi diteboes dengen djawa ploletar" (Soemantri, 1924:86).

Dari kondisi peperangan sekarang, Soedarmo menyarankan agar kaum proletar negeri yang satu dengan proletar negeri yang lain bersatu. Bersatuanya rakyat proletar untuk senjata melawan kapitalis supaya tidak dipermainkan sebagai alat untuk berperang meluaskan wilayah jajahan. Dengan demikian kaum kapitalis tidak bisa memperdaya kaum proletar untuk keuntungannya.

d. Kaum buruh tidak bisa memerintah negeri. Soedarmo menanggapi pernyataan ini dianggap penghinaan bagi kaum buruh. Soedarmo memberikan contoh laju perdagangan dan membangun rumah-rumah yang besar atau gedung-gedung pemerintahan, semua itu dilakukan oleh buruh. Majikan tinggal memerintah sambil menunggu datangnya laba.

"Siapakah jang menggalang roemah besar-besar dan gedonggedong jang indah-nindah itoe? Soedah tentoe boeroeh! Si modal tinggal mengisep tjeroetoe sadja. Siapakah jang mendjadi soldadoe? Soedah tentoe boeroeh! Padahal militerisme boekan ketjil ertinja dalem 
doenia kemodalan. Djadi dalem ini perkara ertinja boeroehlah jang menjalanken praktijk oentoek mengatoer negeri.

Padahal pengetahoeanpengetahoean jang bisa membikin kemadjoean manoesia itoe tidak haroes didjoealnja sebagai barang dagangan, tetapi haroes diberiken pertjoema bagi kesedjahteraan negeri. Lagi poela semoea peladjaran itoe sekarang terisi dengen ratjoen kemodalan jang bisa menjempitken angaen-angen boeroeh (Soemantri, 1924:8687).

Para serdadu adalah kalangan buruh yang sumbangsihnya sangat besar dalam dunia pemodalan. Hal ini buruh yang menjalankan praktik untuk mengatur negeri. Sebab para buruh tidak bisa berpendidikan tinggi akibat dari para pemodal memberikan tarif pendidikan yang tidak murah, sehingga tidak heran kalau buruh menjadi bodoh. Pendidikan dianggap Soedarmo tidak sepatutnya untuk dijadikan seperti barang komoditi tapi harus diberikan gratis untuk kemajuan negeri. Selain itu, kurikulum pendidikan dinilai Soedarmo sudah berisi racun kemodalan sebagai upaya untuk menyempitkan pemikiran buruh.

e. Dua golongan kasta musti ada. Soedarmo kembali menegaskan sanggahan Abdulgani, bahwa sebab dari keributan dalam pergaulan hidup lantara adanya dua kelas. Masingmasing kelas berkehendak untuk memperoleh penghasilan untuk lebih banyak. Dua kasta ini selamanya akan mengalami pertentangan kalau tidak dilenyapkan dari muka bumi. Pertentangan ini bisa berakhir kalau dua kasta ini berubah menjadi satu kasta, yaitu "kasta manusia".

"Masing-masing kasta minta lebih banjak dapet bagian oentoek keperloeannja. Inilah jang menimboelken pertentangan kasta jang kita seboet: "Klas sentrijd". Djadi selama 2 kasta ini masih ada, selama itoe djoega pergaoelan hidoep ta' bisatenterem. Dan lantaran ini tidak heran bahwa partai-partai dalem pergaoelan hidoep laloe timboel sebagai djamoer. Oleh karena itoe maka pertengkaran dalem doenia ta' ada habisnja, sebeloemnja semoea kasta-kasta jang berlaian keperloeannja itoe dilenjapken dan laloe hanja ada satoe matjam kasta sadja, jaitoe kasta manoesia" (Soemantri, 1924:8889).

Setelah menjawab sanggahan Abdulgani, Soedarmo turun dari mimbar. Masa teriak dan bertepuk tangan sangat meriah. Abdulgani hanya diam tidak mampu balik menanggapi ulang atas pernyataan Soedarmo. Pernyataan Sariman tidak ditanggapi dalam oleh Soedarmo, bisa jadi pernyataan Sariman dianggapnya sebagai bentuk apresiasi dan mempertegas propaganda Soedarmo. Tepat jam 11 malam vergadering ditutup voorzitter.

Sariman sebagai simbol kaum kromo, vergadering dinilai sebagai hal yang aneh dan terkagum-kagum. Buat kaum kromo, pengalaman di vergadering-vergadering itu sama sekali baru, luar biasa, menggairahkan, dan aneh (Shiraishi, 2005: 89-90). Takashi menggambarkan pada saat vergadering SI berlangsung, banyak dari seorang petani di desa, mendengarkan kasak-kusuk tentang ceramah propaganda, lalu berjalan kaki bersama teman-teman dan sanak saudaranya ke tempat vergadering. Di sana ia melihat dan mendengar hal-hal yang belum pernah diketahui ataupun disangkanya. Ia mengalami dunia baru di mana tata hierarki Jawa Belanda ditiadakan. Para pejabat Belanda dan Bumiputera sambil mengatakan pada hadirin bahwa semua orang Bumiputera bersaudara dan sama-sama manusia seperti orang Belanda.

Propaganda yang diutarakan Soedarmo intinya mengenalkan ideologi internasionalisme kepada masa vergadering. Soedarmo mampu membangkitkat minat dan 
perhatian pada masa. Keberhasilan propaganda Soedarmo ini bertujuan memberikan pendidikan politik agar mereka tidak lagi dibodohi oleh para penguasa (pemerintah) dan pemodal pabrik tebu. Hal demikian, membuat rakyat menjadi pintar dan dapat bersikap kritis terhadap kesewenag-wenangan dan eksploitasi lahan garapan penduduk.

Dengan begitu, perbedaan kelas di dalam masyarakat dan penghisapan oleh pihak kapitalis bisa lenyap dari muka bumi, sesuai pengharapan ideologi internasionalisme. Persatuan yang teguh sesama kaum buruh yang tertindas, dapat diciptakan untuk kekuatan yang mampu memaksa kapitalis tunduk pada tuntutan-tuntutan rakyat. Pada akhirnya, kesejahteraan rakyat akan bisa tercapai, semua menjadi sama dan sederajat.

Dalam surat kabar Soeara Ra'jat, Soe Hok Gie (1999: 25), mengutip konsep-konsep "kaum marxis" ini jelas terbayang tendensitendensi nihilis. Mereka sadar bahwa untuk melawan penindasan, kalau perlu menjalankan gerakan-gerakan bawah tanah dan secara samar-samar menganjurkan teror. Rakyat dan buruh hanya dapat dipersatukan manakala mereka sadar akan keperluannya. Penyadaran inilah, ideologi internasionalisme yang dikenalkan kepada rakyat dalam novel Rasa Merdika dianggap sebagai tahap awal menyadarkan untuk mampu dimengerti.

Ideologi yang disampaikan Soedarmo hanyalah sebatas gambaran dasar untuk mempengaruhi masa. Beberapa pemikiran sederhana yang berada di lingkungan sekitar dijadikan kristalisasi, agar maksud pemahaman ideologi internasionalisme mampu diserap oleh masyarakat dengan mudah. Masyarakat dalam tataran vergadering novel Rasa Merdika adalah dari berbagai lapisan sosial dan latar belakang pendidikan yang berbeda.

Ideologi internasionalisme, dapat disebut sosialisme internasional atau internasionalisme proletariat masuk ke Hindia Belanda bersamaan dengan komunisme yang dibawa Sneevliet karena internasionalisme yang berhaluan dasar dari filsafat marxis menggunakan revolusi komunis sebagai penggerak menuju komunisme internasional. Konsep dasar ideologi internasionalisme berangkat dari pertentangan kelas, antara kelas kapitalis dan kelas buruh yang sejarah awalnya, kapitalis sudah menjadi sistem yang merugikan kelas pekerja. Sehingga ideologi internasionalisme muncul sebagai perlawan revolusioner kaum buruh untuk menuntut hak-haknya, maka kaum buruh dalam melakukan perjuangannya di negara-negara seluruh dunia harus bersatu menentang kapitalisme. Seperti yang sudah dipaparkan Soedarmo dalam Rasa Merdika, penentangan kelas kapitalis bertujuan untuk menuju pada "kasta manoesia".

Dalam novel Rasa Merdika, pencerita menjadikan tokoh Abdulgani sebagai tokoh yang berhaluan nasionalisme. Soedarmo mengatakan, Abdulgani mempunyai pikiran yang sempit, perlu lagi banyak belajar agar mengerti sebab-sebab timbulnya kemiskinan. Pendek kata, ideologi internasionalisme secara fundamental bertentangan dengan nasionalisme, karena nasionalisme masih melihat bangsa terdiri atas berbagai golongan, belum bisa mengakui sama rata. Nasionalisme memandang semua negara-negara terbagi atas kelas sosial yang berbeda-beda, tujuan yang berbeda, dan dasar negara yang tidak sama.

\section{SIMPULAN}

Tokoh rekaan yang dibangun Soemantri melalui novel Rasa Merdika merupakan peristiwa masanya yang direkam memlalui bahasa fiksi sederhana yang bermuatan idelogi politik internasionalisme. Media karya sastra pada masa sebelum kemerdekaan merupakan alat yang efektif untuk mempengarui pembaca Hindia Belanda karena media cerita waktu itu sangat disukai oleh kalangan masyarakat sebagai sesuatu yang menghibur. Soemantri orang yang berlatar belakang organisasi komunis Hindia Belanda (cabang Semarang) sengaja memanfaatkan narasi sastra untuk memperbaiki nasib golongan manusia yang termiskin, supaya mereka mendapat satu nasib yang sesuai dengan derajat manusia, yaitu dengan memerangi sebab-sebab yang menimbulkan kemiskinan di Hindia Belanda.

\section{DAFTAR PUSTAKA}

Aulia, A. W. (20006). Berjuta-Juta dari Deli Satoe Hikajat Koeli Contract. Gramedia Pustaka Utama.

Damono, S. D. (1999). Politik Ideologi dan Sastra Hibrida. Pustaka Firdaus. 
Gie, S. H. (1999). Di Bawah Lentera Merah. Yayasan Bentang Budaya.

Shiraishi, T. (2005). Zaman Bergerak: Radikalisme Rakyat di Jawa 1912-1926. Pustaka Utama Grafiti.

Shoelhi, M. (2012). Propaganda Dalam Komunikasi Internasional. Simbiosa Retakama Media.

Soemantri. (1924). Rasa Merdika: Hikayat Soedjanmo. Druk-kerij VSTV.

Sulton, A. (2015). Sastra Bacaan Liar Harapan Menuju Kemerdekaan. Jurnal Bahasa \& Sastra, 15(2).

Sulton, A. (2020). Mas Marco Kartodikromo's
Resistance in 1914-1926: Between Indonesia's Independence Hope and Persdelict Threat. International Journal of Scientific \& Technology Research, 9(1).

Tanah Air Bahasa Jejak Pers Indonesia. (2007). Tim (Iswara N Raditya). I:BOEKOE.

Tickell, P. (2008). Cinta Di Masa Kolonialisme: Ras dan Percintaan Dalam Sebuah Novel Indonesia Awal. Yayasan Obor Indonesia.

Yuliati, D. (2000). Semaoen: Pers Bumiputra dan Radikalisasi Sarekat Islam Semarang. Bendera. 